\title{
Research on the Influence of Xi'an Free Trade Area on Shaanxi 's Economic Development
}

\author{
Yanlin $\mathrm{Si}^{1, \text { a }}$ \\ ${ }^{1}$ Xi'an International University, Shaanxi Xi'an 710077 \\ aemail,
}

Keywords: Xi'an Free Trade Area; Shaanxi Economy; Impact Research

\begin{abstract}
Xi'an Free Trade Area in August 2016 formally approved, since the FTA approval plan proposed, Shaanxi has been in multi-party preparation, all-round preparation, governor Hu peace hosted the fourth executive meeting of the Shaanxi provincial government, The main content of the meeting is how to speed up the opening of the free trade area and other related work arrangements. Under the formal rule of law, the development of Xi'an Free Trade Zone has provided great impetus to the overall economic construction and development of Shaanxi Province. Shaanxi has put forward the plan of building a legal system with distinct characteristics, and will promote the construction of Xi'an Free Trade Zone Shaanxi economic development as the primary development task. This paper studies the impact of Xi'an Free Trade Area on the economic development of Shaanxi.
\end{abstract}

\section{Introduction}

On March 28, 2015, the National Development and Reform Commission, the Ministry of Foreign Affairs and the Ministry of Commerce jointly issued the "Vision and Action to Promote the Economic Development of the Silk Road and the Maritime Silk Road in the 21st Century", whereby the Silk Road Economic Zone Of the construction and development of Chinese economic development has become one of the important strategies [1]. The new Silk Road economic belt development and construction, and the region has a great relevance, east of the Asia-Pacific economic circle, west of the European economic circle, the "road" is known as the strong potential of the economic road. Xi'an Free Trade Zone approved, for Shaanxi Province is undoubtedly a surprise news for the economic development of the Northwest region provides an important support, not only to speed up their own economic construction in Shaanxi Province, neighboring provinces and cities can benefit, And international trade convergence.

\section{Relevance Thinking of Xi'an Free Trade Zone Approved}

Xi'an Free Trade Zone and the official development in August 2016 and it is with the "new situation, new ideas and new starting point" for the main development of private trade ideas, access to the attention of all sectors of the Chinese people [2]. March 2017, the development and international influence forum held in Xi'an, China and thousands of foreign lawyers to participate in the forum, gathered in Xi'an, the free trade area after the approval of foreign investment opportunities and risks, free trade area - China Enterprise internationalization of the new path, PPP model to help the development of the free trade zone legal practice and other hot topics in-depth discussion. The development of the forum for the future development and development of free trade area in Shaanxi Province provides an important proposal. In this regard, we are worth pondering is that in recent years, Shaanxi economic construction and development is quite stable, the policy guidance and support are perfect, but did not let Shaanxi into the national economic growth and technological innovation frontier position, then the free trade area Approval and development of what can bring to Shaanxi, in the face of this rare opportunity, how will Shaanxi meet new challenges and rapid development. Chinese economic system in recent years are in the rapid and stable development of Chinese GDP in 2009 catch up with Japan; in 2010 exports catch up with Germany, Chinese economic development in recent years, the successful transformation. The development of 
globalization led to the international economy continued to remain in the doldrums, in the financial crisis intensified, the economic situation is not stable, at any time under the turbulent competitive pressure, China put forward the "economic belt along the way", "free trade area construction", " Investment bank "and other multi-economic strategic plan, so further to determine the sustainable development of Chinese economy, steady progress in the healthy development trend.

\section{Economic profile of Xi'an Free Trade Area}

The real development scope of Xi'an Free Trade Zone (Shaanxi Free Trade Zone) is 119.95 square kilometers. The area consists of three development zones: (1) Center Area: The area is located in the economic development area of Xi'an Center, with a total of 87.76 square $\mathrm{Km}$, of which Shaanxi Xi'an Export Processing Zone Area A covers an area of 0.75 square kilometers, Shaanxi Xi'an Export Processing Zone B area of 0.79 square kilometers, Xi'an high-tech comprehensive bonded area covers an area of 3.64 square kilometers, Shaanxi Xi Xian Bonded Logistics Center to focus on high-end economic system construction, including high-end manufacturing industry, aviation industry, domestic and international logistics, the center of the central area of the focus of the development of new industries and high-tech industries, The development of the film area is the primary transformation area of service trade, which can promote the overall economic system construction, and deepen the comprehensive plan in science and technology, technology, education and production, and build the core area into the core of the high-end industry Heavy ground. (2) Xi'an International Port Area: The area of the implementation area of 26.43 square kilometers, the region's development tasks for the international trade, financial services, tourism exhibition, e-commerce, etc., the region into a "one way" financial open international transit hub The (3) Yangling Demonstration Zone: The area of the implementation of the area of 5.76 square kilometers, the focus of the development of the film industry for agricultural science and technology innovation, is the focus of agricultural economic development demonstration area, will be built as "one way" new era of high-end agriculture Center area [3].

\section{The Impact of Xi'an Free Trade Area on Shaanxi's Economic Development}

New Pattern of Shaanxi Economy Opening to the Outside World. The establishment of Xi'an Free Trade Zone has its own special advantages. In terms of location, Xi'an is located in the Central Plains region, which can undertake the two major regions of the eastern and western regions of China, and also the strategic plan of the Silk Road Economic Zone. It is the only way to connect Asia, Hub of the central city, but also bear the main channel of our major traffic routes, but also an important hub of information construction. Xi'an as the starting point of the Silk Road area, Shaanxi undertakes the overall economy to play a huge role [4]. Xi'an Xianyang International Airport is Chinese fifth largest airport, in the field of aviation, air transport in the Midwest has an irreplaceable role, the construction of Xi'an Free Trade Area in Shaanxi overall economic system in the construction of the key areas of development, In recent years, Shaanxi's economic construction level has been ranked first in many areas in the northwest, with a sound and systematic basis for stable industrial construction. On this basis, Shaanxi has accumulated rich experience in economic development and construction, Open, Xi'an itself has a relatively sound economic and industrial base, in high-tech, advanced technology, high-end industrial manufacturing, tourism, services, etc. have a complete industrial chain, this time the approval of the free trade area is undoubtedly open to Shaanxi To provide a new opportunity for development in the soft environment, both the hard environment at the same time with the basis of benign development, while maintaining the characteristics of Shaanxi self-economic, cultural heritage, but also comprehensively improve the level of its opening up.

New Directions for Shaanxi's Economic Redeployment. Unlike the other free trade areas examined and approved by the state, the strategic positioning of Shaanxi Free Trade Zone has been closely followed by the strategic policy of the Silk Road economic zone, which is an important 
manifestation of the national economic strategy along the inland "along the way". The construction of Xi'an Free Trade Zone also has a positive effect on the economic strategy of the western development. On this basis, Shaanxi Province attaches great importance to and constantly puts forward innovative measures to explore new paths and strive to develop the economy better and faster. Since the approval of the free trade area, after several months of implementation of the plan, Shaanxi Province, drawing on Shanghai, Tianjin, Fujian, Guangdong and other free trade area of the available experience, effectively promote the efficiency of their own development, and achieved remarkable results [5]. Shaanxi is in the initial stage of the construction of the free trade area, drawing on the mature experience of other regions at the same time, also clear their own advantages, do a good job of self-positioning, identify the right direction in the construction of free trade area, integration of internal advantages of resources, New plan to deploy, comprehensive and coordinated development, adjust the strategic pattern. It can be said that the construction of Xi'an Free Trade Area is the driving force and tonic agent of Shaanxi as a whole plan. In the overall scheme of Shaanxi Free Trade Area, the 43 regional innovation contents of the free trade block can be supplemented by the docking of national strategic plan included in the overall plan to deploy the program, and strive to become a national dual standard demonstration base.

Optimize the Overall Economic Investment Environment in Shaanxi. Xi'an, the construction of the free trade area of Shaanxi's overall economic investment environment has a huge role in optimizing, Xi'an original Samsung, Huawei, Skyworth and other large Chinese brands of industrial base, but also the development of electronic technology industry, in addition, the national aerospace electronic software Modern high-tech technology industry also has a complete basis for Chinese aviation. Aerospace development has a great role in promoting. The construction of Xi'an Free Trade Zone has attracted many colleges and universities in Shaanxi, including other high-tech and high-tech talents in mainland China, and strengthened the development rate of various fields in Shaanxi [6]. Since the construction of Xi'an Free Trade Zone since the construction, in addition to attracting many talents to seek development again, combined with the status of their own inventory management, the overall investment management system has been established, this will be a greater degree of optimization of the overall economic investment environment in Shaanxi to improve the regional investors For the traditional development of the western region of the traditional bias, for the construction and development of Shaanxi economic system to attract more manpower and capital, but also for more people to provide jobs, to solve the employment of the majority of people, to enhance the Shaanxi The overall income level and the quality of life for the overall economic construction in Shaanxi Province and lay a good foundation.

Lead the Coordinated Development of Shaanxi Economy. The central government for the construction of the free trade area, although there is no special policy support, but to the overall construction of Shaanxi provides an opportunity to give their innovative policy opportunities. Learn from Chinese other free trade area of economic construction experience, the construction of Xi'an Free Trade Area is to lead the overall economic development of Shaanxi important opportunity for the development and development of the free trade area, although the pilot test base as the core, but led the surrounding economy development is an inevitable trend, Shaanxi Province as a superior province of Xi'an, the construction and development of the free trade area should also focus on Shaanxi's overall economic construction planning and deployment, can not appear to focus on individual development, which is contrary to the concept of national economic strategy the Fujian Free Trade Area, for example, the national key test task of 186, there are 98 to expand the opening, we can see the development of FTA into the mature stage, driven by the region's overall economic system development. It can be seen that the construction of Xi'an Free Trade Area is an important opportunity to promote the overall economic development of Shaanxi.

\section{Conclusion}

Shaanxi is one of the provincial administrative units in China, the provincial capital is Xi'an, located in the northwest inland lots, across Chinese two largest watersheds, the Yellow River and the Yangtze River, China is the east, middle, northwest, southwest of an important hub The Shaanxi's 
economic construction level has been ranked first in many areas in the northwest, with a sound and systematic basis for stable industrial construction. On this basis, Shaanxi has accumulated rich experience in economic development and construction, while the Xi'an Free Trade Zone Approved for many years in Shaanxi preparations to enjoy and create the greatest value of economic construction. The construction of the free trade area provides a strong support for the overall economic construction of Shaanxi, and promotes the economic system of Shaanxi. The industrial chain is facing international development. Of course, the current economic construction of Shaanxi Province is still at the initial stage. A few months time, Shaanxi Province in the financial, insurance, trade, intermediary and other industries have made good achievements, I believe the future, along with the country's overall economic development pace, continue to accumulate experience, to the economic tide in the stability of the win, continuous progress.

\section{References}

[1] Zhao Liang, Chen Shumei. "Free Trade Zone Driven by Economic Growth" - A Comparative Study of China-Japan Free Trade Area, China-Japan-Korea Free Trade Area and RCEP [J]. Economic Review, 2015, 01: 92-102

[2] Zhao Fei. Foreign exchange management policy to support the Silk Road economic zone Xi'an free trade experimental park construction reference and exploration[J]. Western Finance, 2015,01: 77-80.

[3] Zhao Qing. Construction of Silk Road Economic Zone Xi'an Free Trade Area Feasibility Analysis and Policy Suggestions[J]. Western Finance, 2016, 04: 72-74.

[4] Wang Gang Gaoli. Xi'an: to free trade area construction as an opportunity to force reform and government functions change [N]. Shaanxi Daily, 2017-04-06003

[5] Zhou Bin. Shaanxi economy to maintain the "catch up beyond" the strategic path - based on "thirteen" Shaanxi comprehensive building a well-off society [J]. New West (theoretical), 2016,24: $14-16$.

[6] Ge Weiwei, Yang Pengsheng. Increased pre-tune fine adjustment to promote the steady growth of Shaanxi economy - Shaanxi Provincial Economic Society 2012 annual meeting and theoretical seminar view $[\mathrm{J}]$. New West (theoretical), 2012, Z6: 9-10 + 4 . 